The potential health, financial \& environmental impacts of dieselgate in Ireland

Shreya Dey, Brian Caulfield and Bidisha Ghosh*

Department of Civil, Structural \& Environmental Engineering, Trinity College Dublin, Dublin, Ireland

*Corresponding Author Email: bghosh@tcd.ie 


\section{The potential health, financial \& environmental impacts of dieselgate in Ireland}

The transportation sector is the greatest contributor to air pollution. With the booming demand for transportation, reducing the pollution has become one of the main concerns of researchers. EPA emission standards are designed to protect air quality and human health. Diesel Euro 5 NOx has become a matter of disquiet since it has been found that NOx emissions are significantly exceeding the standard limit. This paper presents a study to estimate the disparity in real world NOx emission levels resulted from all diesel Euro 5 passenger cars (PC) and light commercial vehicles (LCV) that are present in Ireland. NOx emission levels calculated based on laboratory test results, on-road measurements and COPERT 4 model were compared. Additionally, NOx emission levels from the defective Volkswagen models have been calculated to quantify the effect of the Volkswagen scandal on Ireland. Impacts of excess NOx emissions on health and cost have also been presented.

Keywords: dieselgate; Volkswagen scandal; COPERT 4; euro 5 light duty vehicles; NOx emissions; health impact of $\mathrm{NOx}$ 


\section{Introduction}

Air pollution is associated with 7 million premature deaths annually (WHO, 2014) and Nitrogen Oxides (NOx) are classic air pollutants which are responsible for a wide variety of environmental, health and financial damages. NOx pollution contributes to atmospheric levels of NOx, fine particulate matter, and ground-level ozone. Exposure to these pollutants has been linked with a range of serious health effects, including increased asthma attacks and other respiratory diseases (USEPA, 2016). The impact handbook (Korzhenevych et al., 2014) reported that one tonne of NOx causes 5688 euros of financial damage which includes damage cost of health, crop, material and biodiversity, in Ireland.

Ireland has relatively good air quality compared to other European Union (EU) Member States and meets the EU specified guidelines (EPA, 2017). However, while ambient NOx levels are within limit in Ireland at the monitoring locations, the NOx emission levels failed meet the national emission ceilings (NEC) in 2010 and continue to be above the NEC target (EPA, 2016). Diesel engines tend to emit a higher percentage of $\mathrm{NO}_{2}$ (EPA, 2015) and it is expected that the NOx emission levels in Ireland will increase due to a significant increase in the number of diesel vehicles in the fleet since 2008 and due to the dieselgate where certain diesel Euro 5 PC models were found to be cheating the emission test with the help of a defeat device fitted with a software which turns the full emissions controls for NOx on only during the test and at other times the 2.0 litre and 3.0 litre engines emit NOx up to 40 times and up to nine times the standard, respectively (USEPA, 2016). These Euro 5 engines were originally planned to reduce the ambient $\mathrm{NO}_{\mathrm{X}}$ concentration due to better vehicular technologies producing less $\mathrm{NO}_{\mathrm{X}}$ emission than their predecessors which may not be the reality. The rise in the number of 
diesel passenger vehicles can be linked to the Irish Carbon-based vehicle tax system whereby vehicles purchased from 2008 onwards would be taxed based on their $\mathrm{CO}_{2}$ emissions intensity rather than their engine capacity (the previous approach) (Giblin \& McNabola, 2009). This resulted in a shift in new vehicle purchasing patterns from petrol to diesel. Figure 1 shows the new car registration pattern over the period 2007-2015 (SIMI, 2016).

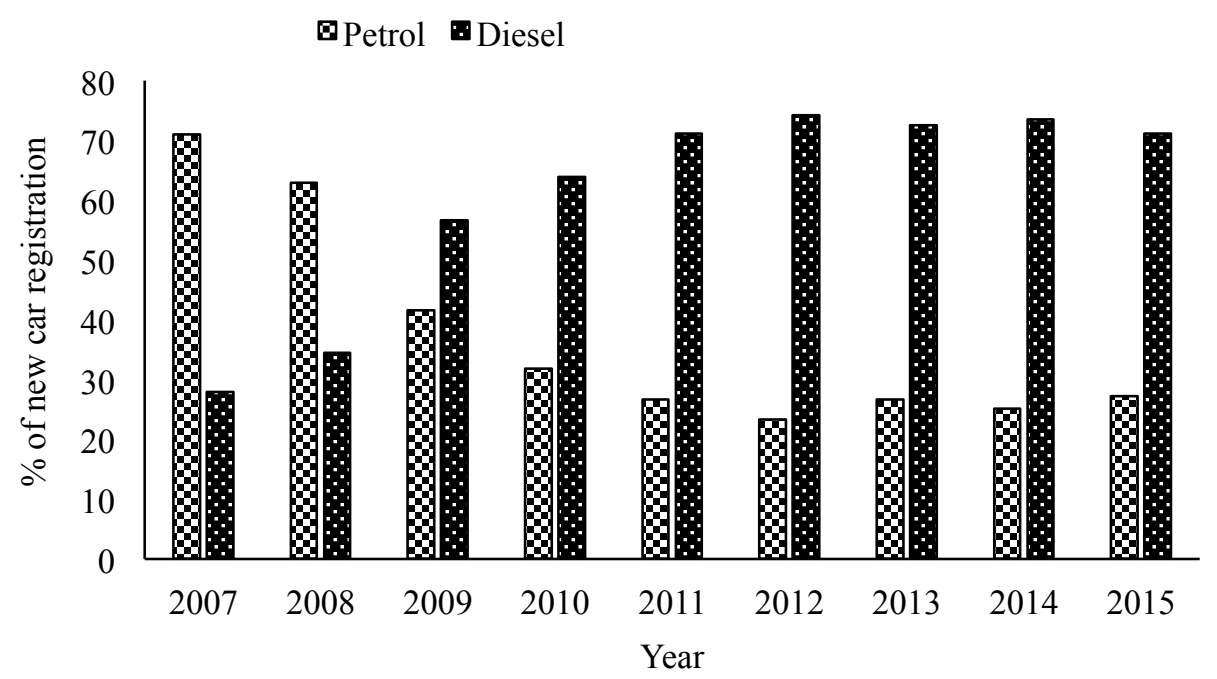

Figure 1. New car registration pattern over 2007-2015

In Volkswagen (VW) scandal, VW and Audi passenger cars have been found to violate Euro 5 emission standards resulting in higher NOx emission levels from these vehicles than from vehicles with properly operating emission control systems. Even though emission standards became stringent with every progressive emission standard directive, in reality, in-service emissions from diesel vehicles have not reduced at all through the Euro 1-5 emission standards (Moody and Tate, 2017). Transport \& Environment (2016) has reported that Volkswagen Euro 5 LCVs produce cleanest vans when empty but exceeds the limit by $225 \%$ when full. Also, it has been suspected that a total of 21.4 million Euro 5 PCs and 2.2 million Euro 5 LCVs across Europe are faulty (Transport \& Environment, 2016). It is important to investigate whether the 
discrepancies between the real-world emission levels and the lab tested levels are adjusted in assessing the environmental impacts of NOx in Ireland. However, this study only focuses on the impact of excess NOx from Euro 5 LDVs. The NOx emissions behaviour of in service Euro 6 vehicles under real driving was explored by Moody and Tate (2017) who reported that Euro 6 diesel cars show a significant improvement over Euro 5 diesel cars.

COPERT 4 is one of the most widely used models in Europe for calculating emissions from road transportation which are used for national inventories as well as for target setting for future. Thus, it is important for the model to reflect the real world emissions well. COPERT 4 is a recommended model by European Environmental Agency (EEA) to calculate emission for more than 30 European countries (EMISIA, 2014). It is developed based on a large database which includes information on vehicle fleet, speed related emission factors $(\mathrm{EF})$, fuel related information, annual mileage and average speed for each vehicle category and capable of calculating emissions from a wide range of pollutants (Ong et al., 2011). COPERT is also used in Ireland to estimate emission levels of air pollutants (Caulfield, 2009; Brady and O‘Mahony, 2011; Doorley et al., 2015; Alam et al., 2015). It has been identified that the model developed EFs do not comply well with real world emission values as measured in lab test or PEMS and it is not only Volkswagen but all the other Euro 5 vehicles that might be emitting more NOx than the standard limit (Ntziachristos et al., 2016).

Achour et al. (2011) used a portable Gas Analyzer to validate COPERT 4 EFs and found that COPERT 4 underestimates the NOx emissions. Berkowicz et al. (2006) used Operational Street Pollution Model (OSPM) and Kousoulidou et al. (2011) used Portable Emissions Measurement Systems (PEMS) to verify COPERT EFs and both have reported significant underestimation of NOx concentration by COPERT. From the 
aforementioned studies, it can be concluded that COPERT always has a tendency to underestimate NOx and this might be because of COPERT considers average speed whereas in real driving scenario there are many other factors involved that affects the emission profile such as, driving behaviour and frequent speed changes which affect the emission levels.

In tests conducted by TNO (2016) on wide range of Euro 5 makes and models, it was observed that the NOx values obtained in real world conditions in a lab or on the road are significantly higher than that obtained from the type approval test or Euro 5 limit. It has also been pointed out that, earlier, the model EFs could partially be linked to the real-world emissions considering the difference in them with respect to driving behaviour under real-world condition. But now the difference in emissions are much higher even when the vehicles are driven under such conditions that are comparable to the type approval test condition (TNO, 2016). Weiss et al. (2011) found the NOx values for diesel Euro 5 cars to be in the range $0.4-1 \mathrm{~g} / \mathrm{km}$ which is 3-5 times more than the European driving cycle values.

This paper intends to study the environmental impact in terms of excess emission by Euro 5 light duty vehicles (LDV) i.e. PCs and LCVs in Ireland based on all the reported facts on dieselgate. The first objective of this paper is to study the NOx emission levels from all the Euro 5 PCs and LCVs in Ireland. This situation is considered and studied based on researches where it has been found that the real world EFs are lot higher than the euro standard limit. But exactly which models or if all the models are faulty or fitted with defeat device are not known. Thus, the emission levels are tested considering all the Euro 5 PCs and LCVs to see the overall quantity of excess emission.

As the VW scandal came in light, it has been identified that specific VW and Audi models (USEPA, 2016) are cheating the emission standard. The second objective of this 
study is to see the effect of VW scandal in Ireland by quantifying the extra emission by reported VW and Audi models. Transport \& Environment (2016) has reported that not only specific VW and Audi PCs but many other LDVs are suspected to be cheating the emission standards. The third objective has been designed to study the NOx emission levels resulted from all PC and LCV models of VW and Audi. This will give an idea how much a single brand of vehicle which has been proved to be cheating, is contributing. Additionally, this paper also studies the health and financial impacts of the excess NOx discharged from all the Euro 5 PCs and LCVs.

The next section describes the methodology, followed by presentation and discussion of the results and conclusion.

\section{Methodology}

The potential effect of dieselgate in Ireland has been investigated in this study. The discrepancy between the on-road emissions and the modelled emissions obtained using COPERT 4 is also explored along with the health \& cost implications of the hidden NOx.

The investigation was carried by designing different actual and hypothetical scenarios. This section presents the methodology followed to find out the NOx emission levels from all diesel Euro 5 LDVs using COPERT 4 (v11.3), lab test results, PEMS measurements and also based on euro standards. PEMS records the emissions when vehicle is driven on road and the measurements reflect the on-road emission levels. In order to achieve the objectives of the paper, different emission scenarios were designed and they are summarised in table 1 . The scenarios are also described in details in this section.

Table 1. Summary of the designed scenarios. 


\section{Scenarios}

\section{Description}

\begin{tabular}{ll}
\hline Scenario 0- & NOx emission levels as per euro standard specification \\
Euro standard & for euro 5 PCs and LCVs \\
scenario & \\
\hline Scenario 1A- & NOx emission levels from Euro 5 PCs and LCVs \\
COPERT base & calculated using COPERT \\
scenario &
\end{tabular}

\begin{tabular}{ll}
\hline $\begin{array}{l}\text { Scenario 1B-PEMS } \\
\text { base scenario }\end{array}$ & $\begin{array}{l}\text { NOx emission levels based on the PEMS measurements } \\
\text { and includes all the Euro 5 PCs and LCVs in the fleet in }\end{array}$ \\
\hline Scenario 1C- & NOx emissions based on lab test measurements for all \\
lab test base & the euro 5 PCs and LCVs present in the fleet in Ireland \\
scenario & NOx emissions resulted from reportedly (USEPA, 2016) \\
\hline Scenario 2A- & faulty VW and Audi models present in the Irish PC fleet \\
VW COPERT & and calculated using COPERT \\
base scenario & NOx emissions from the reportedly faulty PC models \\
\hline Scenario 2B- & based on PEMS measurements \\
VW PEMS & models based on lab test results \\
base scenario & \\
\hline Scenario 2C- VW & NOx emission levels from the reportedly faulty PC \\
lab test base scenario &
\end{tabular}




\begin{tabular}{l} 
Scenario 3A- $\quad$ NOx emissions considering if all the VW and Audi PCs \\
VW PC \\
hypothetical \\
scenario \\
\hline Scenario 3B- \\
VW in the Irish PC fleet are faulty \\
hypothetical \\
scenario
\end{tabular}

\section{Scenario 0- Euro standard scenario}

This section describes the expected emission levels following the Euro standard specifications for Euro 5 PCs and LCVs. The standard emission levels for all the vehicles were calculated using the following equation,

$$
\mathrm{E}_{\text {istd }}=\mathrm{N}_{\mathrm{i}} * \mathrm{M}_{\mathrm{i}} * \mathrm{EF}_{\text {euro }} * 10^{-6}
$$

$E_{\text {istd }}$ is the NOx emissions (ton) in the year i following the euro standard specification; $\mathrm{N}_{\mathrm{i}}$ is the number of PCs or LCVs in year $\mathrm{i} ; \mathrm{M}_{\mathrm{i}}$ is the average annual mileage $(\mathrm{km})$ in year $\mathrm{i} ; \mathrm{EF}_{\text {euro }}$ is the standard NOx emission factor $(\mathrm{g} / \mathrm{km})$ for Euro $5 \mathrm{PC}$ or LCV.

Euro standard NOx concentration is taken as $0.18 \mathrm{~g} / \mathrm{km}$ for PCs (EEA, 2007) and $0.28 \mathrm{~g} / \mathrm{km}$ for LCVs (TNO, 2015).

\section{Scenario 1A-COPERT base scenario}

In this scenario the vehicular NOx emission levels resulted from the existing Euro 5 and LCV fleet in Ireland were calculated by COPERT 4 (v11.3) using the default emission factors. Depending on the extent of data availability, three different approaches namely, Tier 1, Tier 2 and Tier 3 can be used to calculate emissions (EEA, 2016). COPERT uses the Tier 3 approach which is most accurate among them and uses detailed activity data 
(average speed and kilometres travelled) corresponding to each technology class as well as mode. In COPERT, the following set of equations are used to calculate the total emissions (Ntziachristos and Zissis, 2014),

$$
\mathrm{E}_{\text {Total }}=\mathrm{E}_{\text {Hot }}+\mathrm{E}_{\text {Cold }}
$$

where, $\mathrm{E}_{\text {Total }}$ is the total emissions of a pollutant; $\mathrm{E}_{\mathrm{Hot}}$ is the emissions during stabilised engine operation (hot exhaust emissions) and $\mathrm{E}_{\text {Cold }}$ is the cold start emissions that is the emissions during transient thermal engine operation. The hot exhaust emission is calculated using the following equation,

$$
\mathrm{E}_{\mathrm{Hot} ; \mathrm{i}, \mathrm{k}, \mathrm{r}}=\mathrm{N}_{\mathrm{k}} * \mathrm{M}_{\mathrm{k}, \mathrm{r}} * \mathrm{EF}_{\mathrm{Hot} ; \mathrm{i}, \mathrm{k}, \mathrm{r}}
$$

where, $\mathrm{E}_{\mathrm{Hot}}, \mathrm{i}, \mathrm{k}, \mathrm{r}$ is the hot exhaust emissions of the pollutant $\mathrm{i}(\mathrm{g})$, produced in the period concerned by vehicles of technology $k$ driven on roads of type $r ; N_{k}$ is the number of vehicles (veh) of technology $\mathrm{k}$ in the period concerned; $\mathrm{M}_{\mathrm{k}, \mathrm{r}}$ is the mileage per vehicle $(\mathrm{km} / \mathrm{veh})$ driven on roads of type $r$ by vehicles of technology $\mathrm{k}$; $\mathrm{EF}_{\mathrm{Hot} ; \mathrm{i}, \mathrm{k}, \mathrm{r}}$ is the emission factor $(\mathrm{g} / \mathrm{km})$ for pollutant $\mathrm{i}$, relevant for the vehicle technology $\mathrm{k}$, operated on roads of type $\mathrm{r}$. Cold-start emissions are introduced into the calculation as additional emissions per $\mathrm{km}$ using the following formula,

$$
\mathrm{E}_{\text {Cold } ; \mathrm{i}, \mathrm{k}}=\beta_{\mathrm{i}, \mathrm{k}} * \mathrm{~N}_{\mathrm{k}} * \mathrm{M}_{\mathrm{k}} * \mathrm{EF}_{\mathrm{Hot} ; \mathrm{i}, \mathrm{k}} *\left(\mathrm{e}^{\mathrm{Cold}} / \mathrm{e}^{\mathrm{Hot}}{ }_{\mid \mathrm{i}, \mathrm{k}}-1\right)
$$

where, $\mathrm{E}_{\mathrm{Cold}}$; $\mathrm{i}, \mathrm{k}$ is the cold-start emissions of pollutant $\mathrm{i}$ (for the reference year), produced by vehicle technology $\mathrm{k} ; \beta_{\mathrm{i}, \mathrm{k}}$ is the fraction of mileage driven with a cold engine or the catalyst operated below the light-off temperature for pollutant $i$ and vehicle technology $\mathrm{k} ; \mathrm{N}_{\mathrm{k}}=$ number of vehicles (veh) of technology $\mathrm{k}$ in circulation; $\mathrm{M}_{\mathrm{k}}$ $=$ total mileage per vehicle $(\mathrm{km} / \mathrm{veh})$ in vehicle technology $\mathrm{k} ; \mathrm{e}^{\mathrm{Cold}} /\left.\mathrm{e}^{\mathrm{Hot}}\right|_{\mathrm{i}, \mathrm{k}}=\operatorname{cold} / \mathrm{hot}$ emission quotient for pollutant $\mathrm{i}$ and vehicles of $\mathrm{k}$ technology.

For this study, overall Euro 5 fleet data were obtained from Department of Transport, Tourism and Sport (DTTAS) by considering total number of newly registered vehicle 
since the introduction of Euro 5 vehicles (i.e. over the period of 2011-2015, RSA). Average annual mileages were calculated for each year and mileage shares were assumed to be $15 \%, 9 \%$ and $76 \%$ for urban, rural and highway driving respectively (Brady and O`Mahony, 2011). The NOx emissions were then calculated for each year separately (2011-2015) for PCs as well as LCVs and added up to obtain the overall NOx emissions from Euro 5 PCs and LCVs.

\section{Scenario 1B-PEMS base scenario}

PEMS base scenario calculates the actual quantity of the NOx emissions from Euro 5 LDVs to show how much the Euro 5 LDVs possibly be emitting while on-road compared to the euro standard emission levels as calculated in Scenario 0 and also, to show the quantity of overestimated (for Euro 5 PC) and ignored (for Euro 5 LCV) emissions by COPERT 4. In order to estimate the on-road emissions, urban, rural and highway emissions were calculated separately using COPERT and then modified to reflect the real-world NOx emissions. NOx emissions for urban driving condition were found by keeping Urban driving share as $100 \%$ and the same for rural and highway as zero. The similar approaches were followed while calculating emissions for rural and highway driving. Annual mileage values were disaggregated by their respective percentage of driving mode shares. To get the on-road emission values, NOx concentrations $(\mathrm{g} / \mathrm{km})$ which are based on significant number of on-road measurements and lab tests (Ntziachristos et al., 2016) were taken as reference, the values have been presented in table 2 and table 3. EFs from real-world lab tests were found to be very close to that of COPERT 4. But the differences between emission values obtained from COPERT 4 and 
Table 2. NOx EFs $(\mathrm{g} / \mathrm{km})$ from the graph (Annexure) for urban, rural and highway for passenger cars.

\begin{tabular}{lllll}
\hline Driving mode & Euro 5 & COPERT & PEMS EFs & Difference \\
& Standard EFs & EFs & & between \\
& & & & COPERT and \\
& & & & PEMS EFs (\%) \\
& & & & -14 \\
\hline Urban & 0.18 & 0.76 & 0.88 & +123 \\
\hline Rural & 0.18 & 0.49 & 0.22 & +74 \\
\hline Highway & 0.18 & 0.61 & 0.35 &
\end{tabular}

on-road measurements are quite significant and both are much higher than the Euro 5 NOx limit. The percentage differences between the COPERT and PEMS estimated concentration values $(\mathrm{g} / \mathrm{km})$ were calculated. These percentage differences were used to estimate the on-road emission levels.

Table 3. NOx EFs $(\mathrm{g} / \mathrm{km})$ from the graph (Annexure) for urban, rural and highway for light commercial vehicles.

\begin{tabular}{|c|c|c|c|c|c|c|}
\hline Driving & Euro 5 & COPERT & PEMS & Difference & Lab test & Difference \\
\hline \multirow[t]{5}{*}{ mode } & Standard & EFs & EFs & between & EFs & between \\
\hline & EFs* & & & COPERT & & COPERT \\
\hline & & & & and PEMS & & and lab \\
\hline & & & & EFs $(\%)$ & & test EFs \\
\hline & & & & & & $(\%)$ \\
\hline Urban & 0.28 & 0.78 & 1.55 & -50 & 0.90 & -13 \\
\hline Rural & 0.28 & 0.64 & 1.52 & +58 & 0.72 & -11 \\
\hline Highway & 0.28 & 1.25 & 1.64 & +24 & 1.16 & +8 \\
\hline
\end{tabular}

*varies with respect to the weight, the highest among them is presented here. 
Concentration values from real-world lab cycle tests were found to be higher than model estimated emission factors for urban and rural roads, but on-road measurements were even higher in all the driving conditions and all the estimated values were significantly higher than the standard Euro 5 NOx limit.

Real-world emission levels were calculated by multiplying the separate emissions by a factor equal to the percentage differences (see table 2 and table 3) between COPERT EFs and PEMS EFs to assess the real-world NOx emission levels. These individual emission levels calculated under urban, rural and highway driving conditions were then summed up to represent the total on-road NOx emission level. The same methodology was followed to acquire emission for each year from 2011-2015. Similarly, real world emission levels for Euro 5 LCVs were calculated.

\section{Scenario 1C-lab test base scenario}

Lab test base scenario presents the quantity of Euro $5 \mathrm{NOx}$ emissions based on lab test results. Similar procedure, as was followed to obtain NOx emissions based on PEMS measurements, was also followed to achieve lab test emissions from Euro 5 PCs and LCVs. In this case the percentage differences (see table 2 and table 3 ) found between COPERT 4 emission factors and lab test emission factors were used to modify emission values calculated by COPERT 4. It can be observed in table 2 that for Euro 5 PCs, the PEMS and lab test emission factors are very close. Thus, it is considered that NOx emission levels estimated by COPERT 4 are consistent with those resulted from lab tests. Therefore, PC NOx emissions have not been calculated separately and lab test base scenario only presents results for Euro 5 LCVs.

\section{Scenario 2A-VW COPERT base scenario}


VW base scenario conveys the NOx emitted by the fleet of vehicles fitted with defeat devices as reported by USEPA. Table 4. presents the VW and Audi passenger car models that have been reportedly found to be cheating the NOx emissions,

Table 4. Affected VW and Audi passenger car models (USEPA, 2016).

\begin{tabular}{ll}
\hline Affected 2.0 litre diesel models & Affected 3.0 litre diesel models \\
\hline Jetta & Volkswagen Touareg \\
Jetta Sportswagen & Porsche Cayenne \\
Beetle & Audi A6 Quattro \\
Beetle Convertible & Audi A7 Quattro \\
Audi A3 & Audi A8 \\
Golf Sportwagen & Audi A8L \\
Golf & Audi Q5 \\
Passat & Audi Q7 \\
\hline
\end{tabular}

Specific models (Table 4) of VW and Audi passenger cars with 2.0L and 3.0 L were extracted from the overall database of Irish Motor Industry (SIMI, 2016) and NOx emissions were then calculated using COPERT 4. Input parameters such as speed, mileage share, average annual mileage etc. were considered to be same as those in base scenario.

\section{Scenario 2B-VW PEMS base scenario}

This section presents the actual quantity of NOx discharged from USEPA reported VW and Audi models based on PEMS measurements. To calculate emissions measured by PEMS, similar approach was followed as PEMS base scenario i.e. emissions were calculated separately for different driving modes using COPERT and revised to calculate real-world emission levels as recorded using PEMS.

\section{Scenario $2 C-V W$ lab test base scenario}


This section presents the NOx emission levels exhausted by faulty VW and Audi models as per lab test results. The similar procedure, as followed in case of lab test base scenario to estimate emission for overall Euro 5 fleet, was also used to obtain NOx emission levels from VW and Audi PCs in lab tests.

\section{Scenario 3A-VW PC hypothetical scenario}

Hypothetical Scenarios are designed to explore the effect of circumstances if all 59527 VW and Audi Euro 5 PCs (SIMI, 2016) and 12337 VW Euro 5 LCVs in Ireland are faulty. Based on the reports (Transport \& Environment, 2016; Ntziachristos et al., 2016), it would be worth assuming that it is not only the USEPA reported VW and Audi models but all the VW Euro 5 PCs are equipped with defeat devices. Hence, the following hypothetical situations were tested to measure the excess amount of NOx. This section presents NOx emission levels from all the aforementioned VW scenarios i.e. VW COPERT base scenario, VW PEMS base scenario and VW lab test base scenario, but for overall VW and Audi Euro 5 car fleet in Ireland. Total number of all VW and Audi models in Ireland were extracted from the overall dataset of Irish Motor Industry (SIMI, 2016). NOx emissions for all VW and Audi models were then estimated using the similar methodology as used to calculate the same for reported VW and Audi models.

\section{Scenario 3B-VW LCV hypothetical scenario}

In this section NOx emissions of all VW Euro 5 LCVs are presented. Number of VW LCVs present in Ireland were obtained from Irish Motor Industry (SIMI, 2016) database. Number of Audi LCVs are negligible, hence ignored. Emissions were calculated by all three methods, i.e. COPERT 4, Lab test and PEMS following the similar approach as mentioned in real-world base scenario and lab test base scenario.

\section{Impacts of $N O x$}


The health and financial impact of the hidden NOx caused due to dieselgate in Ireland has been calculated following the methods described in this subsection. The health impact of NOx emission has been calculated using Burden of disease (BOD) approach (WHO, 2013). Burden of Disease (BOD) is a measure of the sum of Years of Life Lost (YLLs) and Years of healthy Life lost due to Disability (YLDs) and is referred as Disability Adjusted Life Years (DALYs). In this study, the unit DALY value reported by Tang et al. (2015) for European countries has been multiplied by total extra NOx emissions in order to obtain the extra number of DALYs resulted due to the hidden NOx from Euro 5 LDVs. Tang et al. (2015) have found that $1 \mathrm{~kg}$ of NOx is responsible for 0.9 $10^{-4}$ Disability Adjusted Life Years (DALYs).

The damage costs for NOx from transport in Ireland have been calculated based on updated Handbook on External Costs of Transport (Korzhenevych et al., 2014). This damage cost includes not only health effects of NOx but also its effect on crops, material (e.g. buildings) and biodiversity. Also, mortality incidences per kiloton (kt) of NOx and their corresponding value of statistical life were calculated based on a study by Oldenkamp et al. (2016).

To study the spatial variation of the impact, total excess NOx emissions were distributed over all the counties in Ireland. County-wise population (CSO, 2011) and LDV count (SIMI, 2016) were extracted and plotted as shown in Figure 1. It can be observed from the graph that the $\mathrm{R}^{2}$ value is significantly high, therefore, a linear relationship was assumed between population and vehicle count. 


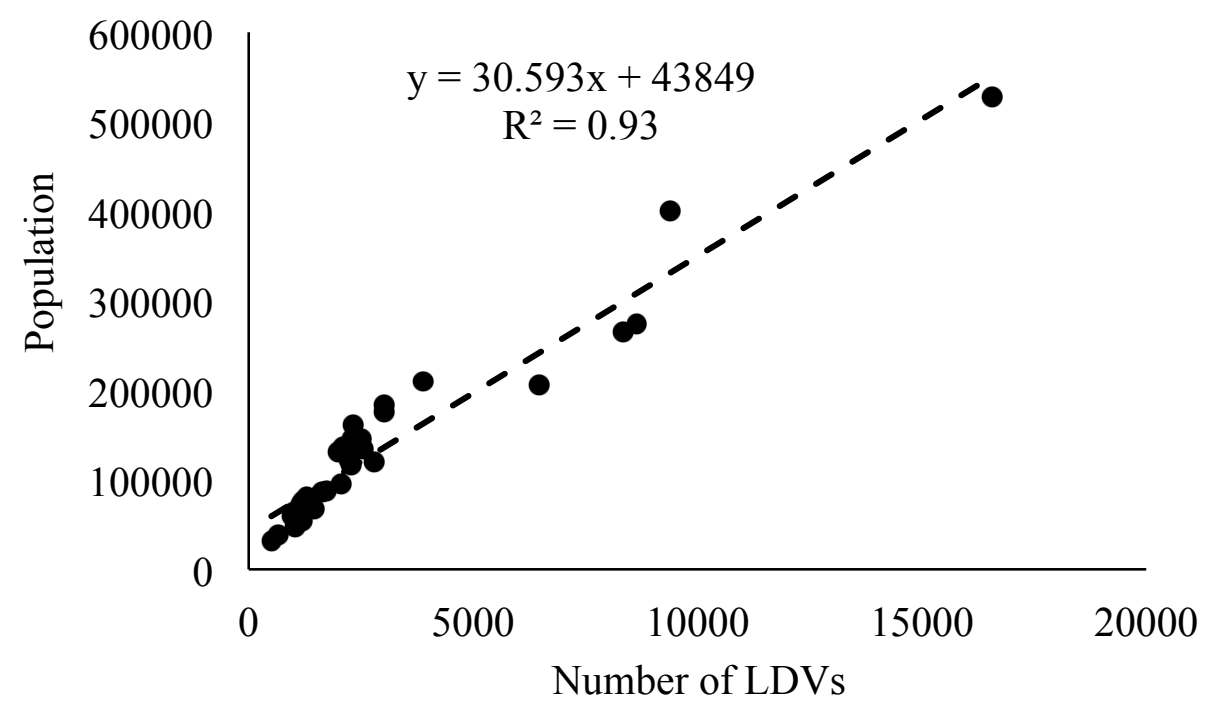

Figure 1. County specific total number of vehicles (PCs $+\mathrm{LCVs})$ vs population

The total excess NOx emission was distributed using the following the equation,

$$
\Delta \mathrm{E}_{\mathrm{ij}}=\Delta \mathrm{E}_{\mathrm{i}} * \mathrm{k}_{\mathrm{ij}}
$$

Where, $\Delta \mathrm{E}_{\mathrm{i}}$ is the total excess NOx emissions in Ireland in the years $\mathrm{i} ; \Delta \mathrm{E}_{\mathrm{ij}}$ is the excess NOx emissions in year $\mathrm{i}$ and county $\mathrm{j}$; $\mathrm{k}_{\mathrm{ij}}$ is spatial emissions distribution factor for county $\mathrm{j}$ in year $\mathrm{i}$, introduced to observe the county specific impacts based on automobile density (Wang et al., 2016). Health and cost impacts were then calculated using this the county specific extra NOx emission.

\section{Data description}

Major input data that were required to calculate emissions from COPERT were, meteorological data (e.g. mean monthly maximum and minimum temperature, humidity), engine size, fuel information, speed $(\mathrm{kmph})$, mileage $(\mathrm{km})$, travel share $(\%)$ and vehicle population. Table 5 shows the main input data and their respective sources. Speeds for urban roads, rural roads and highways were taken as $50 \mathrm{kmph}, 80 \mathrm{kmph}$ and 100kmph respectively (RSA, 2013; RSA, 2015). The data availability on driving mode share in Ireland is very limited, therefore, the mileage shares assumed by Brady and O`Mahony (2011) for Greater Dublin Area (GDA) have been extended to overall 
Ireland. Thus, driving shares have been assumed to be $15 \%, 9 \%$ and $76 \%$ for urban, rural and highway respectively.

Table 5. Input data and their sources.

\begin{tabular}{ll}
\hline Input data & Source of data \\
\hline Meteorological data & MET Eireann: The Irish Meteorological Service Online \\
Fleet data & Department of Transport, Tourism and Sport \\
Speed & Road Safety Authority \\
Mileage data & Central statistics office (Kilometres travelled by road traffic) \\
Volkswagen Euro 5 & Motorstats: The official statistics of the Irish Motor Industry \\
cars and fleet & \\
& \\
configuration
\end{tabular}

The total kilometre travelled by passenger cars were obtained from CSO (2014) and divided by total number of vehicles to get average annual mileage. Information on overall kilometres travelled were available till the year 2014, thus mileage for 2015 was calculated by extrapolating the 2004-2014 data. Figure 2 and Figure 3 show the number of diesel Euro 5 LDVs and average annual mileage respectively. It is perceptible 

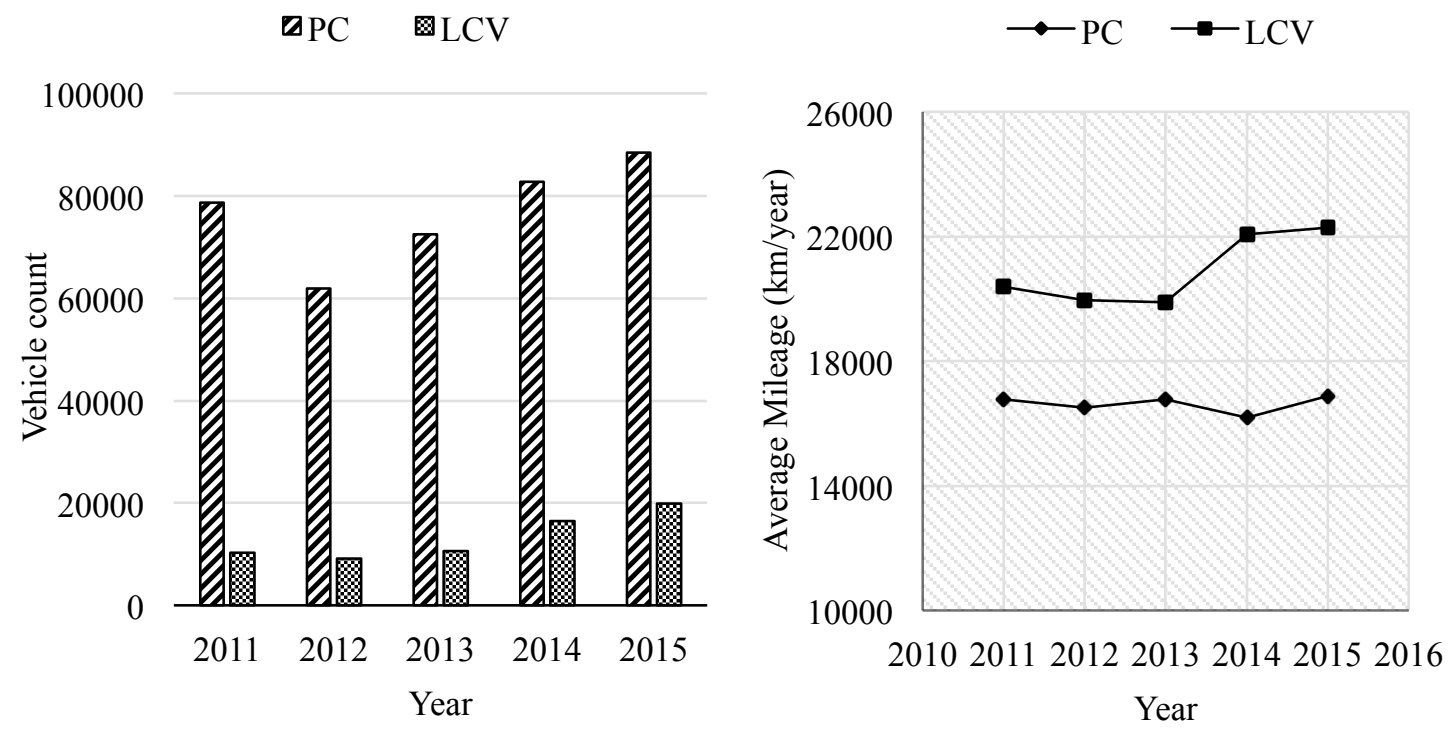

Figure 2. Total number of diesel Euro 5 Figure 3. Annual average mileage LDVs. (km/year).

that there is a significant increase in vehicle numbers every year while the kilometre travelled per year is quite consistent. The LCVs have increased at a higher rate with every year until 2014 while there is a sudden increase in average annual kilometre travelled after 2013. The number of affected diesel Euro 5 VW and Audi passenger cars those are present in Ireland are summarized in Table 6.

Table 6. Number of affected Volkswagen and Audi vehicles.

\begin{tabular}{lllllll}
\hline Year & \multicolumn{2}{l}{ Volkswagen } & Audi & & Total & \multicolumn{2}{l}{$\begin{array}{l}\text { Percentage } \\
\end{array}$} & & & & & of total \\
& $<=2.0 \mathrm{~L}$ & $>2.0 \mathrm{~L}$ & $<=2.0 \mathrm{~L}$ & $>2.0 \mathrm{~L}$ & & fleet \\
2011 & 3499 & 20 & 353 & 36 & 3908 & 5 \\
2012 & 3543 & 21 & 351 & 38 & 3953 & 6 \\
2013 & 3312 & 3 & 602 & 33 & 3950 & 5 \\
2014 & 4088 & 2 & 1939 & 247 & 6276 & 8
\end{tabular}


It can be observed from table 5 that there is a significant increase in overall number after 2013.

\section{Results and Discussion}

The results in terms of total and hidden NOx emissions discharged from potential defective Euro 5 LDVs are presented and discussed in the following subsections.

\section{Existing NOx emission levels in Ireland}

This section presents the emission levels for diesel Euro 5 LDVs in Ireland as calculated using COPERT 4 (v11.3) following the methodologies described in scenario 1A, 1B and 1C. Table 7 presents the overall quantity of NOx emissions (tonnes) estimated by COPERT and PEMS and the last column in table 7 shows the euro standard NOx values in ideal case, i.e. NOx emissions if all the Euro 5 diesel passenger cars had followed the emission standard. A new version (11.4) of COPERT 4 has been released with modified emission factors for Euro 5 LCVs and Euro 6 PCs. The emissions of Euro 5 LCVs have been calculated with the new version of COPERT 4 as well.

Table 7. Vehicle statistics and NOx emission values for passenger cars.

\begin{tabular}{lllll}
\hline Year & Vehicle count & COPERT 4 & On-road & Euro Standard \\
& & $(\mathrm{v} 11.3 / \mathrm{v} 11.4) /$ lab test & \\
\cline { 3 - 5 } & & In Tonnes & \\
\hline 2011 & 78710 & 738 & 485 & 237 \\
2012 & 61910 & 572 & 376 & 219 \\
2013 & 72558 & 680 & 447 & 241 \\
2014 & 82777 & 746 & 491 & 269 \\
2015 & 88485 & 835 & 550 &
\end{tabular}


From table 7, it can be observed that the differences between the model estimated values and PEMS estimates are significant $(52 \%)$. The differences between these estimates might mislead the policymakers. There is huge gap between the euro standard and actual emissions. The emissions obtained via COPERT 4 and on-road measurements are 100-220\% in excess than the euro standard NOx emission levels from diesel Euro 5 PC fleet. The proportion of excess emissions burden on urban, rural and highway is $29 \%, 9 \%$ and $62 \%$ respectively. Table 8 summarizes the overall model estimated and real world emissions from Euro $5 \mathrm{LCVs}$ along with the expected values, i.e. the total NOx emission from Euro 5 diesel LCVs if the standard emission specification was followed.

Table 8. COPERT, On-road and lab test emission values (in tonnes) for LCVs.

\begin{tabular}{lllllll}
\hline Year & Vehic & COPERT 4 & COPERT 4 & On-road & Lab test & Euro \\
& le & $(\mathrm{v} 11.3)$ & $(\mathrm{v} 11.4)$ & & & standard \\
\cline { 3 - 7 } & count & In Tonnes & & & & \\
\hline 2011 & 10355 & 194 & 344 & 252 & 187 & 59 \\
2012 & 9159 & 168 & 297 & 218 & 162 & 51 \\
2013 & 10536 & 192 & 340 & 249 & 185 & 59 \\
2014 & 16457 & 332 & 588 & 431 & 320 & 102 \\
2015 & 19942 & 408 & 723 & 529 & 393 & 124 \\
Total & 66449 & 1293 & 2293 & 1678 & 1247 & 395 \\
\hline
\end{tabular}

From Table 8, it can be noticed that the real world as calculated using PEMS measurements and model estimated emission quantities are about $200-500 \%$ higher than the anticipated values. Even though model estimated urban and rural NOx emission 
factors were observed to be more in lab test outcomes, combined emission amounts calculated by COPERT were estimated to be more than lab test results. On the other hand, the opposite pattern was observed when compared with on-road measurements. Emission values obtained from PEMS measurements were significantly higher than that estimated with COPERT. COPERT 4 (v11.3) underestimates and COPERT 4 (v11.4) overestimates the real-world emission by $23 \%$ and $37 \%$ respectively. COPERT4 (v11.3) was used in Ireland for National Emission Inventory preparation as well as in scientific researches until September, 2016 when COPERT 4 (v 11.4) became available with modified emission factors after the research results (such as, Ntziachristos et al., 2016) pointed out the necessary modification in NOx estimates by previous version of COPERT 4. Thus, all the policy decisions have been made based on the COPERT 4 (v 11.3) emission values as the real -world values in the country. The results from both the versions have been shown to present the difference in estimates between the previous version which has been extensively used in Ireland for calculating road transport emissions and the recent modified version. The discrepancy between the actual NOx discharge and model estimates should be accounted by the researchers and the policymakers, as it might affect many areas given COPERT's extensive application in air quality and impact assessments, projections (energy, $\mathrm{CO}_{2}$, pollutants), urban/regional inventories, new road (road section) construction etc. (Kouridis et al., 2014).

\section{NOx emission levels from affected $V W$-Audi vehicles}

In this subsection, the NOx emission levels calculated based on the methodology described in scenario 2A, 2B and 2C for the defective VW and Audi models in Ireland, are shown. NOx emissions were calculated for those PCs using COPERT 4. Emissions in scenario $2 \mathrm{~B}$ and scenario $2 \mathrm{C}$ were estimated in the similar way as estimated for overall Euro 5 LDV fleet. The expected NOx emissions as per euro specification were 
calculated as well. Figure 4 shows the amount of NOx discharged from the affected vehicles.

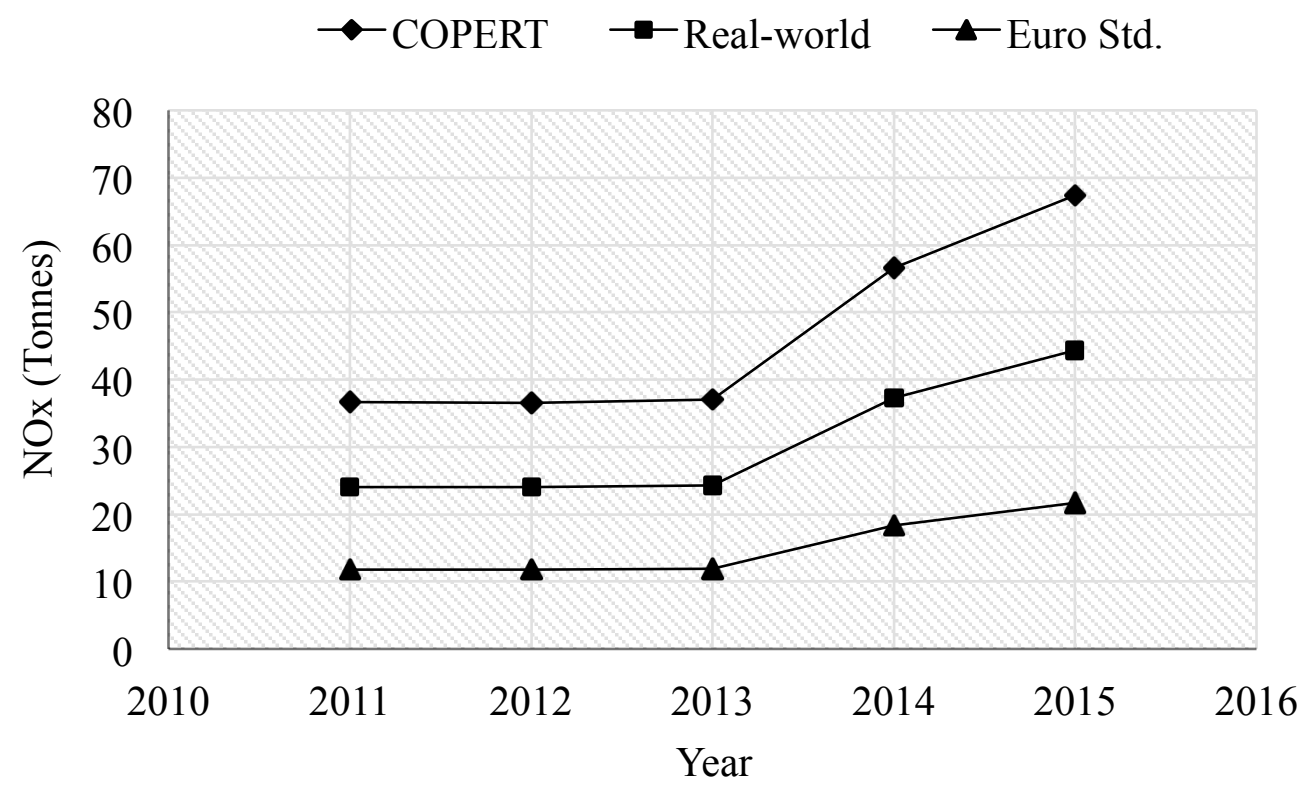

Figure 4. NOx emissions (Tonnes) from affected VW passenger car models in Ireland.

It is observed from the results that the real-world emissions obtained from on-road measurements are almost double than the euro standard values. Only reported models constitute about $6 \%$ of the total excess NOx exhausted by overall diesel Euro 5 vehicles. Thus, it is not only these vehicles but also many other models which are emitting more than the legal limit.

\section{Potential NOx emission levels}

This section presents the NOx levels from hypothetical scenario considerations i.e. NOx emission levels resulted from all VW and Audi Euro 5 LDVs. Table 9 shows the total number of VW and Audi Euro 5 (2011-2015) diesel cars and LCVs in Ireland.

Table 9. Possible faulty VW-Audi (PC+LCV) vehicles in Ireland.

\begin{tabular}{llllll}
\hline Year & PC & & Percentage & LCV & Percentage \\
\cline { 2 - 3 } & & & & & \\
& VW & Audi & Total of total PC & VW & of total
\end{tabular}




\begin{tabular}{lllllll}
\hline & & \multicolumn{3}{c}{ fleet } & LCV fleet \\
\hline 2011 & 8299 & 3037 & 11336 & 14 & 1858 & 18 \\
2012 & 7540 & 3373 & 10913 & 18 & 2326 & 25 \\
2013 & 6792 & 3432 & 10224 & 14 & 2084 & 20 \\
2014 & 8368 & 3967 & 12335 & 15 & 2852 & 17 \\
2015 & 10284 & 4435 & 14719 & 17 & 3217 & 16 \\
Total & 41283 & 18244 & 59527 & 15 & 12337 & 19 \\
\hline
\end{tabular}

Figure 5. shows the NOx emission levels for all $59527 \mathrm{VW}$ and Audi Euro 5 PCs considering if all Euro 5 VW-Audi PCs in Ireland are faulty. The PEMS estimated as well as modelled emission levels are significantly higher than that calculated by following the

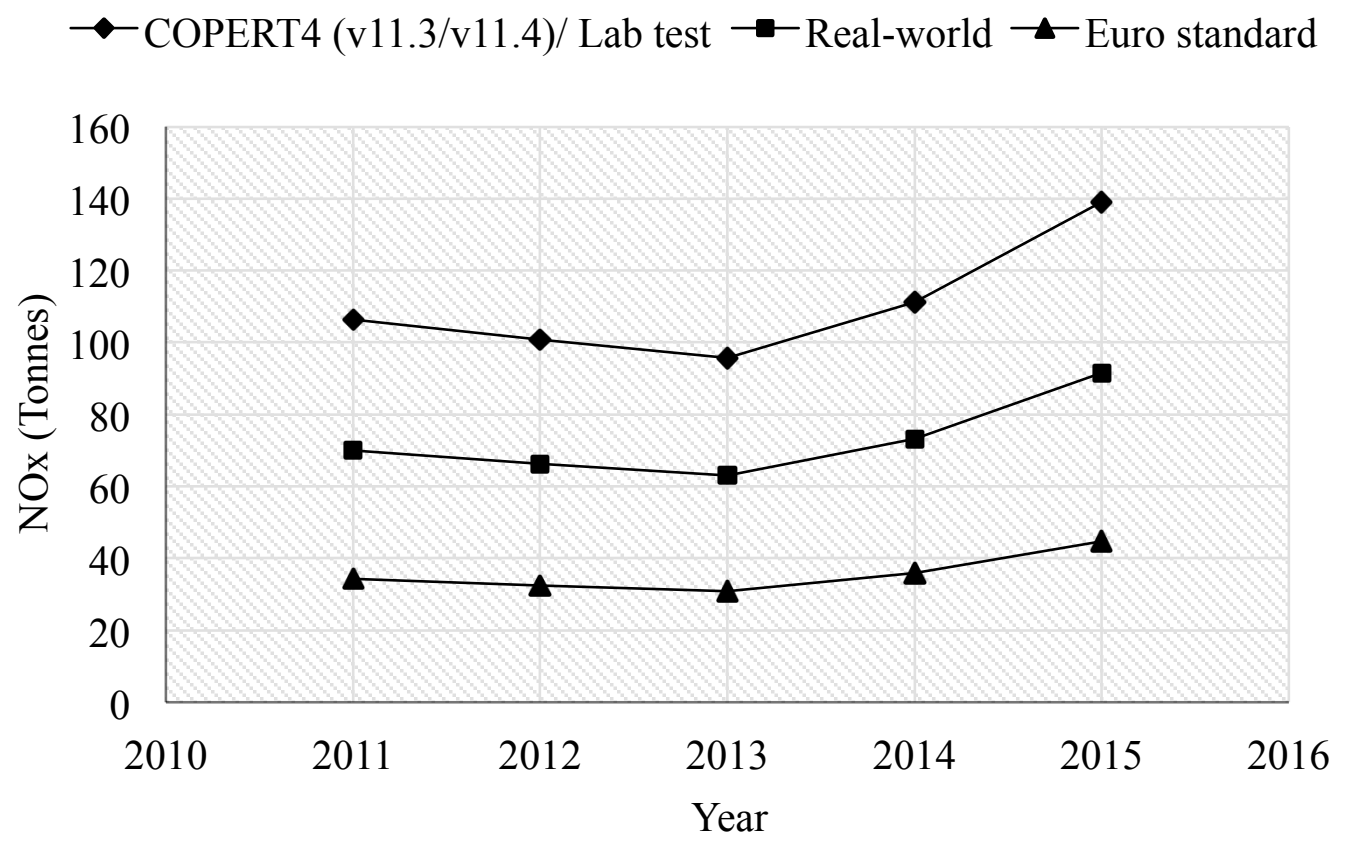

Figure 5. COPERT, PEMS and euro standard emission values (in Tonnes) of VW and Audi PCs. 
Euro standard emission factor for Euro 5 PC. It was observed that PCs of VW and Audi alone produce $15 \%$ of overall extra NOx emissions from diesel Euro 5 PCs. Figure 6 presents the NOx emission levels from 12337 VW Euro 5 LCVs in Ireland assuming if

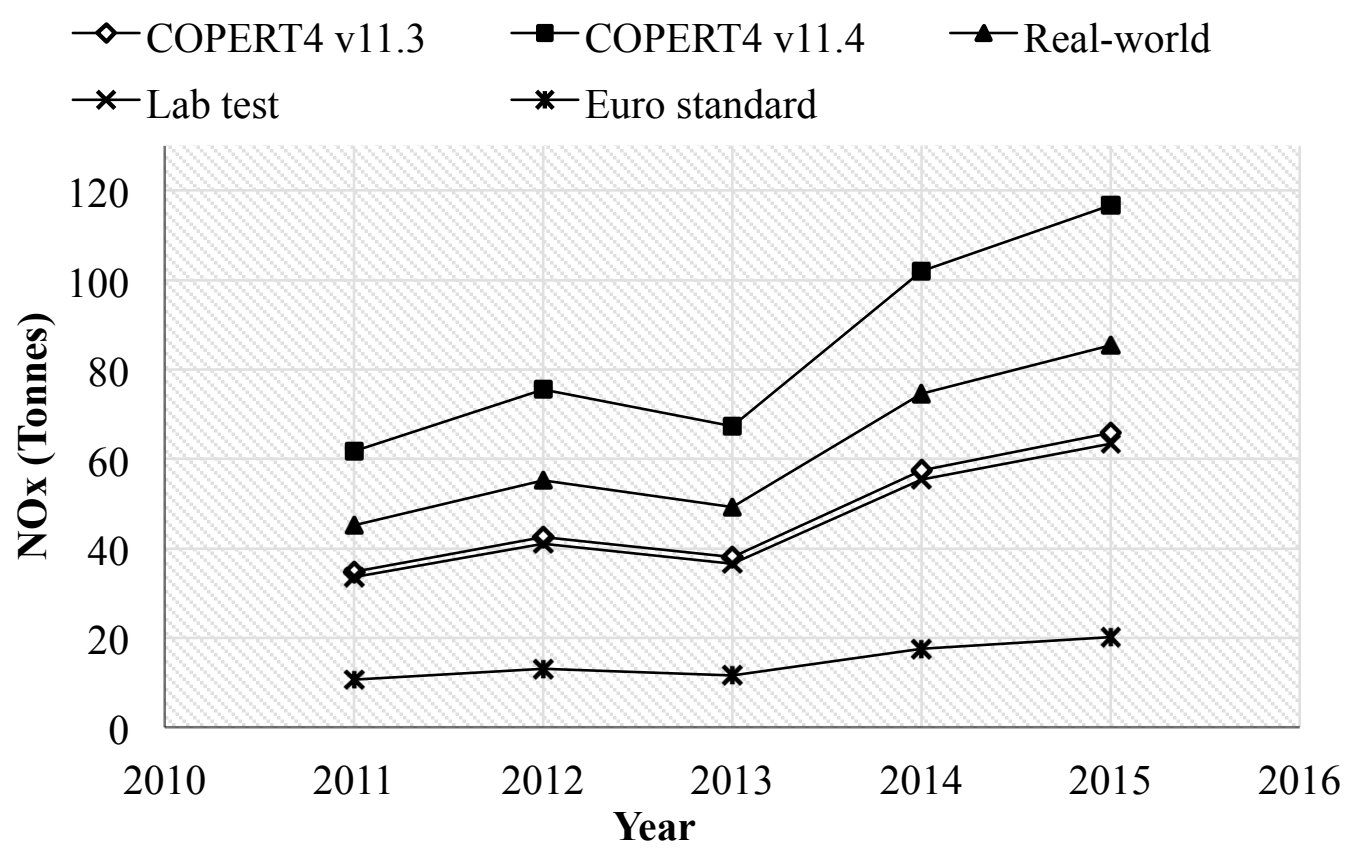

Figure 6. COPERT, PEMS, lab tests and euro standard emission values (in Tonnes) of VW LCVs.

all Euro 5 VW LCVs in Ireland are faulty. It can be observed that VW LCVs solely contribute to significantly large amount of NOx emissions which is $18 \%$ of the excess emissions produced by overall LCV fleet.

\section{Potential health and financial impact}

This section presents the potential health and cost impact of the hidden NOx from Euro 5 PCs and LCVs. It has been assumed that all the vehicles that were newly registered over the period 2011-2015, remained in the market till 2015. Figure 7 shows the total excess NOx exhausted by the Euro 5 PCs and LCVs annually compared to the expected euro standard emission. 


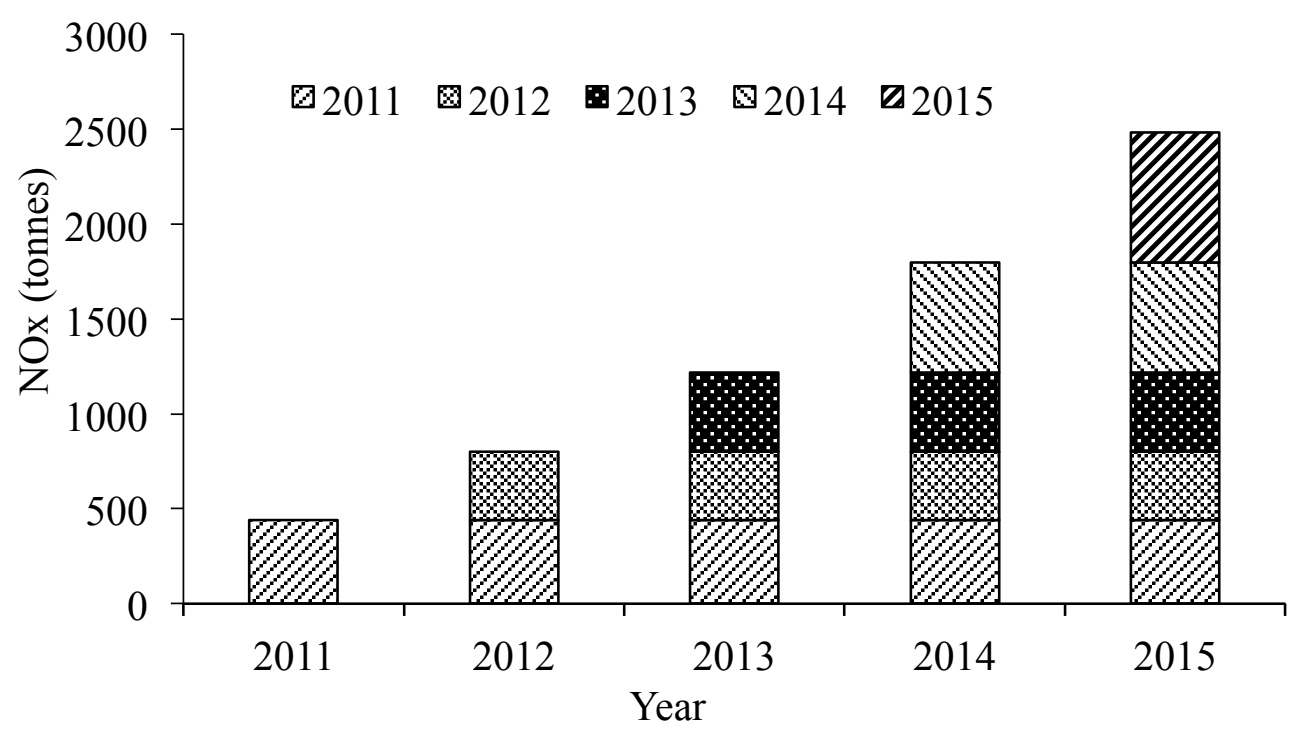

Figure 7. Total excess NOx (tonnes) from all Euro 5 LDVs.

About 451,000 (Figure 2) of allegedly faulty vehicles have emitted 6735.6 tonnes of extra NOx to the atmosphere over the 5 year period. In table 10 the annual extra NOx and their corresponding potential DALYs, mortality incidences and damage costs of the hidden NOx from Euro 5 LDVs are listed. The unit values used to access the BOD and mortality incidences are 90 DALYs/kt (Tang et al., 2014) and 10.23 incidences/kt (Oldenkamp et al., 2016) respectively. The value of statistical life (VSL) was taken as 7.2 million (approximated) euro/death incident (Robinson \& Hammitt, 2015) and the damage cost as 5688 euro/tonne (Handbook, 2014) of extra NOx.

Table 10. Potential health and cost damages due to extra NOx from faulty vehicles.

\begin{tabular}{llllll}
\hline Year & Extra NOx & Additional & Mortality & Additional VSL & Additional \\
& & DALYs & incidences & & Damage cost \\
\hline & $(\mathrm{kt})$ & & & (Million Euro) & (Million Euro) \\
\hline 2011 & 0.44 & 39.64 & 5 & 32.44 & 2.51 \\
2012 & 0.80 & 71.91 & 8 & 58.85 & 4.54
\end{tabular}




$\begin{array}{cccccc}2013 & 1.22 & 109.59 & 12 & 89.69 & 6.93 \\ 2014 & 1.80 & 161.67 & 18 & 132.31 & 10.22 \\ 2015 & 2.48 & 223.40 & 25 & 182.83 & 14.12\end{array}$

It can be observed from the above table that the potential faulty vehicles might have caused damage worth of approximately 540 million euros. The automobile density for a specific county has been calculated by dividing the number of vehicles (SIMI, 2016) in that county by its population $(\mathrm{CSO}, 2011)$ and presented in Figure 8 . The spatial variations of health and cost impacts due to the excess NOx have been shown in Figure 9 and Figure 10.

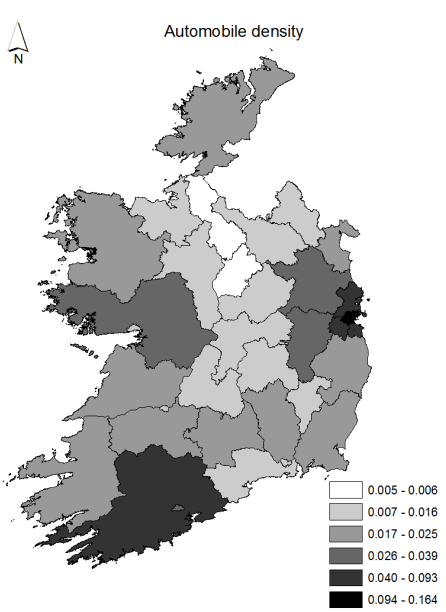

Figure 8. Spatial

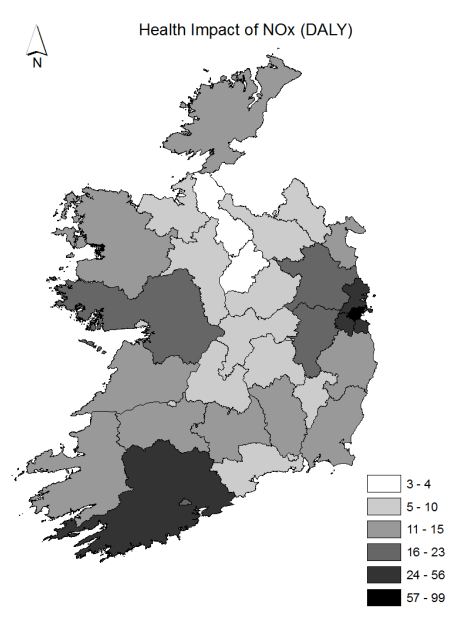

Figure 9. Spatial

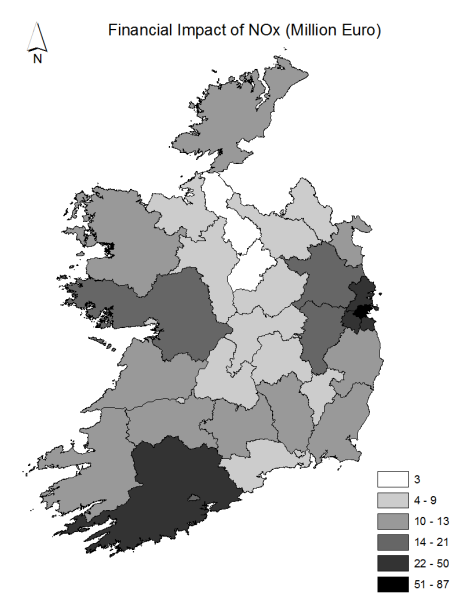

Figure 10. Spatial

distribution of automobile density in Ireland distribution of health impact due to excess NOx

distribution of cost impact due to excess NOx

It can be observed from the figures that the impacts are higher in the areas where the vehicle and population densities are higher. If the faculty vehicles continue to be in use, the number of mortality incidences in the urban areas will be higher provided the dominant impact on those areas. Therefore, this study suggests for immediate action to prevent the future loss especially in the areas with highest impact. 


\section{Conclusion}

This paper aims to quantify the disparity between the expected, modelled, real-world lab tested and PEMS estimated NOx emissions resulted from diesel Euro 5 LDVs that are present in Ireland. It can be observed from the NOx emission levels that even though emission standards became tighter with every progressive euro standard directive (e.g. NOx limit is $0.25 \mathrm{~g} / \mathrm{km}$ for Euro 4 and $0.18 \mathrm{~g} / \mathrm{km}$ for Euro 5), the realworld (PEMS estimates) as well as lab tested emissions are more than the expected emission levels. This clearly indicates that Euro 5 vehicles are not obeying the respective standards. The reason/s behind this excessive discharge of NOx should be examined and measures should be taken to make sure that vehicles follow the euro standard emission limits. Moreover, there is mismatch between COPERT 4 estimated and actual emission levels and the differences are significantly high. COPERT 4 (both v 11.3 and 11.4) overestimated PC NOx emission levels and in case of LCVs COPERT 4 v11.3 underestimated and COPERT 4 v11.4 overestimated the PEMS estimated realworld NOx emissions by considerable amount. Provided COPERT's substantial applicability in many fields, this issue should also be focused on and suitable measures should be implemented accordingly so that COPERT reflects the real emission as accurately as possible.

Even though few Volkswagen and Audi PC models have been proved to be cheating the NOx emission, the results show that the amount of PEMS estimated real-world NOx emissions for all diesel light duty vehicles are huge. All potentially faculty diesel Euro 5 LDVs have emitted in 6740 tonnes of excess NOx in Ireland in last 5 years (20112015). The defective Euro 5 LDVs are probably responsible for 70 death incidences and approximately 606 DALYs. The average lifetime of a car in Europe is around 17 years (Transport \& Environment, 2016) and this means that the Euro 5 LDVs are going to be 
excessively polluting for more than 10 years from now. This will have huge financial and health impacts. Consequently, extensive testing on different Euro 5 and Euro 6 vehicle of various makes and models are required to be carried out. It is also recommended that the tax incentives introduced to encourage the uptake of diesel vehicles should be revised accordingly. More incentives should rather be provided to buy electric vehicles, especially in the urban areas where the automobile density and resulting health impact is high. Also, policies to support phasing out of diesel vehicles as has been planned to be followed in other EU countries should be explored.

\section{Annexure:}

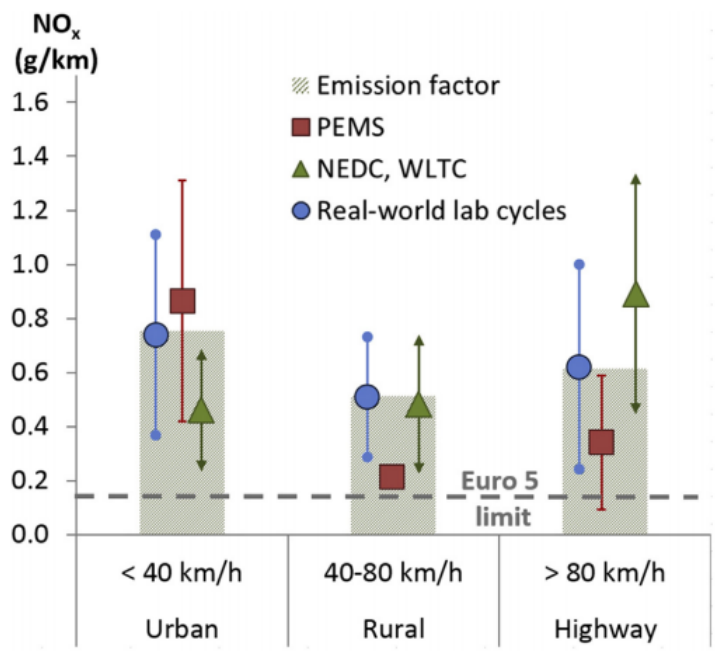

Fig. 1. Simplified current model $\mathrm{NO}_{\mathrm{x}} \mathrm{EFs}$ and measured emission levels for diesel Euro 5 passenger cars. PEMS tests correspond to two vehicles only. Uncertainty ranges
correspond to \pm standard deviation.

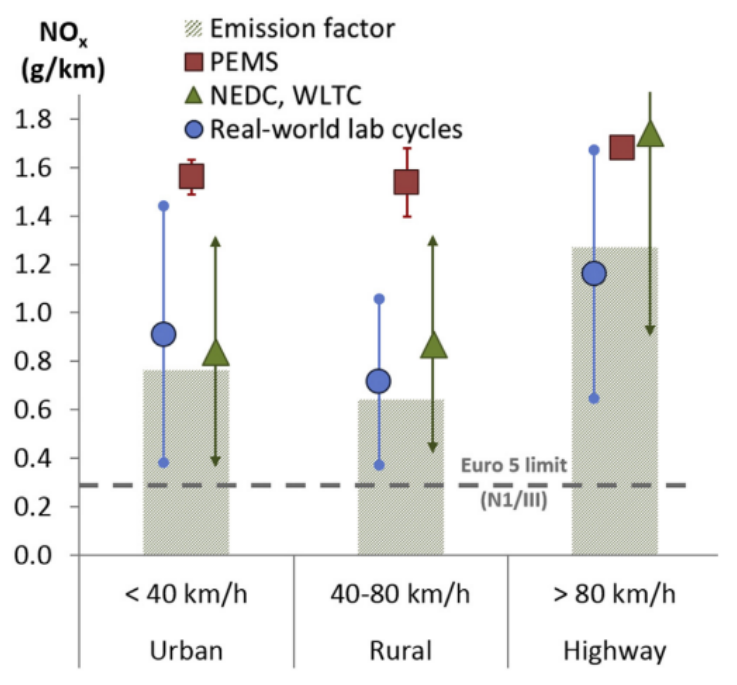

Fig. 2. Simplified current model $\mathrm{NO}_{\mathrm{x}} \mathrm{EFs}$ and measured emission levels for diesel Euro 5 light commercial vehicles. Uncertainty ranges correspond to \pm standard deviation.

\section{Acknowledgement}

The authors would like to thank the Environmental Protection Agency, Ireland for funding this research under the Greening Transport project.

\section{Reference}


Achour, H., A. G. Olabi, and J. G. Carton. 2011. "Estimating Vehicle Emissions from Road Transport, Case study: Dublin City." Applied Energy 88: 1957-1964. doi:10.1016/j.apenergy.2010.12.032.

Alam, Md., S., P. Duffy, B. Hyde, and A. McNabola. 2015. "Restructuring, estimation and back extrapolation of road transport activity data for emissions estimation: 19872013.” Environmental Protection Agency.

Berkowicz, R., M. Winther, and M. Ketzel. 2006. "Traffic pollution modelling and emission data." Environmental Modelling \& Software 21: 454-460. doi:10.1016/j.envsoft.2004.06.013.

Brady, J., and M. O‘Mahony. 2011. "Travel to work in Dublin. The potential impacts of electric vehicles on climate change and urban air quality." Transportation Research Part D 16: 188-193. doi:10.1016/j.trd.2010.09.006.

Caulfield, B. 2009. "Estimating the environmental benefits of ride-sharing: a case study of Dublin." Transportation Research Part D: Transport and Environment 14: 527 531. doi:10.1016/j.trd.2009.07.008.

CSO (Central Statistics Office). 2011. "Population of each Province, County and City, 2011.” CSO. Accessed March 72017.

http://www.cso.ie/en/statistics/population/populationofeachprovincecountyandcity2011/ CSO (Central Statistics Office). 2014. "Kilometres travelled by road traffic." CSO. Accessed May 202016.

http://www.cso.ie/multiquicktables/quickTables.aspx?id=tha10_2

Doorley, R., V. Pakrashi, and B. Ghosh. 2015. "Quantification of the Potential Health and Environmental Impacts of Active Travel in Dublin, Ireland." Transportation Research Record: Journal of the Transportation Research Board 2531: 129-136. doi:10.3141/2531-15. 
DTTAS (Department of Transport, Tourism and Sport). 2016. "Irish Bulletin of Vehicle and driver Statistics" DTTAS, February 16.

http://www.dttas.ie/roads/publications/english/irish-bulletin-vehicle-and-driverstatistics-2015

EEA (European Environmental Agency). 2016. "EMEP/EEA air pollutant emission inventory guidebook 2016." EEA technical report no 21/2016. Accessed March 10 2017.

http://www.eea.europa.eu/publications/emep-eea-guidebook-2016

EMISIA. 2014. "COPERT Countries data." EMISIA. Accessed April 202016. http://emisia.com/products/copert-data

EPA (Environmental Protection Agency). 2016. "Ireland's Environment: An Assessment 2016” EPA, November 2016. Accessed June 212017. http://www.epa.ie/pubs/reports/indicators/SoE_Report_2016.pdf

EPA (Environmental Protection Agency). 2017."Ireland's Environment" EPA. Accessed September 202016.

http://www.epa.ie/irelandsenvironment/air/

Gibin, S., and A. McNabola. 2009. "Modelling the impacts of a carbon emissiondifferentiated vehicle tax system on $\mathrm{CO}_{2}$ emissions intensity from new vehicle purchases in Ireland.” Energy Policy 37(4): 1404-1411.

Kadijk, G., N. Ligterink, and J. Spreen. 2015. "On-road $\mathrm{NOx}$ and $\mathrm{CO}_{2}$ investigations of Euro 5 Light Commercial vehicles" $\quad$ TNO, March 9. https://www.tno.nl/media/4980/nox_and_co2_investigations_of_commercial_vehicles.p df

Kadijk, G., N. Ligterink, P. V. Mensch, and R. Smokers. 2016. "NOx emissions of Euro 5 and Euro 6 diesel passenger cars-test results in the lab and on the road", TNO, March 
9.

http://www.europarl.europa.eu/meetdocs/2014_2019/plmrep/COMMITTEES/EMIS/DV /2016 05-24/TNO_May_report_EN.pdf

Kouridis, C., G. Mellios, and L. Ntziachristos. 2014. "COPERT 4 main elements." Accessed September 202016.

http://emisia.com/sites/default/files/COPERT_4_Statistics.ppt

Kousoulidou, M., L. Ntziachristos, S. Gkeivanidis, Z. Samaras, V. Franco, and P. Dilara. 2010. "Validation of the COPERT road emission inventory model with real-use data." Paper presented at 19th International Emission Inventory Conference, Emission Inventories - Informing Emerging Issues, San Antonio, TX, September 27-30.

Monthly data (The Irish Meteorological Services; accessed September 21, 2016). http://www.met.ie/

Moody, A., and J. Tate. 2017. "In Service CO2 and NOX Emissions of Euro 6/VI Cars, Light- and Heavy- dutygoods Vehicles in Real London driving: Taking the Road into the Laboratory." Journal of Earth Sciences and Geotechnical Engineering 7: 51-62.

Ntziachristos, L., G. Papadimitriou, N. Ligterink, and S. Hausberger. 2016. "Implications of diesel emissions control failures to emission factors and road transport NOx evolution." Atmospheric Environment 141: 542-551. doi:10.1016/j.atmosenv.2016.07.036.

Ntziachristos, L., and S. Zissis. 2014. "Exhaust emissions from road transport." Accessed March 102017.

http://emisia.com/sites/default/files/1\%20A\%203\%20b\%20Road\%20transport\%20GB2 014_latest.pdf 
Oldenkamp, R., R. V. Zelm, and M. A. J. Huijbregts. 2016. "Valuing the human health damage caused by the fraud of Volkswagen." Environment Pollution 212: 121-127. doi:10.1016/j.envpol.2016.01.053.

Ong, H. C., T. M. I. Mahlia, and H. H. Masjuki. 2011. “A review on emissions and mitigation strategies for road transport in Malaysia." Renewable and Sustainable Energy Reviews 15: 3516-3522. doi:10.1016/j.rser.2011.05.006.

Official Journal of the European Union. 2007. "Regulations.” June 29. http://eurlex.europa.eu/LexUriServ/LexUriServ.do?uri=OJ:L:2007:171:0001:0016:EN: PDF

Ricardo- AEA. 2014. "Update of the Handbook on External Costs of Transport, Report for the European Commission: DG MOVE” United Kingdom, January 8. http://ec.europa.eu/transport/sites/transport/files/themes/sustainable/studies/doc/2014handbook-external-costs-transport.pdf

Robinson, L. A., and J. K. Hammitt. 2015. "Research Synthesis and the Value per Statistical Life.” Risk Analysis 35 (6). doi: 10.1111/risa.12366.

RSA (Road Safety Authority). 2013. "Survey of free speed." RSA. Accessed September 122016.

http://www.rsa.ie/en/RSA/Road-Safety/RSA-Statistics/Surveys--Consultations/Speed/ RSA (Road Safety Authority). 2015. "Driving in Ireland.” RSA. Accessed September 12 2016. http://www.rsa.ie/en/RSA/Licensed-Drivers/Driving-in-Ireland/ RSA (Road Safety Authority). 2016. "The Introduction of Euro 5 and Euro 6 Emissions Regulations for Light Passenger and Commercial Vehicles." RSA. Accessed November 142016.

http://www.rsa.ie/Documents/Vehicle\%20Std\%20Leg/Emissions\%20regs/Euro\%205\% 20and\%20Euro\%206\%20Emissions\%20Reg\%20light\%20passengercommvehicles.pdf 
SIMI: The Society of the Irish Motor Industry (The official statistics of the Irish Motor Industry; September 21, 2016).

http://www.beepbeep.ie/stats

Tang, L., T. Nagashima, K. Hasegawa, T. Ohara, K. Sudo, and N. Itsubo. 2015. "Development of human health damage factors for PM2.5 based on a global chemical transport model." The International Journal of Life Cycle Assessment. doi:10.1007/s11367-014-0837-8.

Transport \& Environment. 2016. “Dieselgate: Who? What? How?” Accessed November 92016.

https://www.transportenvironment.org/publications/dieselgate-who-what-how USEPA (United States Environmental Protection Agency). 2016. "Frequent Questions about Volkswagen Violations.” USEPA. Accessed September 162016.

https://www.epa.gov/vw/frequent-questions-about-volkswagen-violations\#health USEPA (United States Environmental Protection Agency). 2016. "Learn About Volkswagen Violations.” USEPA. Accessed September 162016.

https://www.epa.gov/vw/learn-about-volkswagen-violations

USEPA (United States Environmental Protection Agency). 2016. "Volkswagen Light Duty Diesel Vehicle Violations for Model Years 2009-2016." USEPA. Accessed September 52016 .

https://www.epa.gov/vw

Wang, T., M. Jerrett, P. Sinsheimer, and Y. Zhu. 2016. "Estimating PM2.5-associated mortality increase in California due to the Volkswagen emission control defeat device." Atmospheric Environment 144: 168-174. doi: 10.1016/j.atmosenv.2016.08.074.

Weiss, M., P. Bonnel, R. Hummel, U. Manfredi, R. Colombo, L. Gaston, P. L. Lijour, and M. Sculati. 2011. "Analyzing on-road emissions of light-duty vehicles with 
Portable Emission Measurement Systems (PEMS)." JRC Scientific and Technical Reports. Accessed February 2017.

http://publications.jrc.ec.europa.eu/repository/bitstream/JRC62639/jrc_62639_final.pdf

West Virginia University Media Centre. 2015. "WVU study found elevated levels of emissions from Volkswagen vehicles". West Virginia University Media Centre. September 122016.

http://wvutoday-archive.wvu.edu/n/2015/09/24/wvu-study-found-elevated-levels-ofemissions-from-volkswagen-vehicles.html

WHO (World Health Organisation). 2014. WHO media centre. Accessed September 12 2016.

http://www.who.int/mediacentre/news/releases/2014/air-pollution/en/

WHO (World Health Organisation). 2013. "WHO methods and data sources for global burden of disease estimates 2000-2011" Geneva: Department of Health Statistics and Information Systems, November 2013.

http://www.who.int/healthinfo/statistics/GlobalDALYmethods_2000_2011.pdf 